British Journal of Psychiatry (1988), 152, 424-439

\title{
Correspondence
}

Editor: Greg Wilkinson

Contents: Hospital Anxiety and Depression Scale/ Pseudo-AIDS, AIDS panic, or AIDS phobia/Selfinflicted eye injuries/Paranoid psychosis and AIDS/ Ganser syndrome/Age of onset in schizophrenia/ Anthropology and psychiatry/The dopamine hypothesis, viral theory of schizophrenia, and season of birth/Barking mad/Screening for hepatitis B in the mentally handicapped/Maternity blues and postpartum euphoria/Characteristic plasma hormone changes in Alzheimer's disease/Down's syndrome with mania/Dopamine hypothesis of neuroleptic drug action/Lithium, psoriasis, abnormal glucose tolerance, and thyroid dysfunction/Disulfiram reaction during sexual intercourse/Prasad's syndrome/ 'Criminal Law and Psychiatry'.

\section{Hospital Anxiety and Depression Scale}

SIR: May I comment upon the correspondence (Journal, December 1987, 151, 861-862) arising from the study of depressed mood after stroke and the use of our Wakefield Depression Scale. The observation that this scale was an unsuitable instrument for the study is certainly correct. In fact, the concept of 'depression' covered by that instrument is too broad, since it is composed of a wide spectrum of symptoms, including those of anxiety and of somatic reference. We have long considered it to be redundant, and now advocate the use of the Hospital Anxiety and Depression (HAD) Scale (Zigmond \& Snaith, 1983). The HAD Scale was designed for use with patients suffering from physical illness, and is an improvement on other self-assessment instruments since it avoids items, e.g. insomnia and anorexia, which are as likely to result from physical illness as from mood disorder. The HAD Scale provides a clear separation, in its two subscales, between the constructs of anxiety and depression and its ability to do so has recently been upheld in a validation study (Bramley et al, 1988). The depression subscale concentrates on the anhedonic state, which we take to be the nearest clinical marker to the biogenic mood disorder likely to respond to physical treatment (Snaith, 1986). In fact, the need to detect this state in medical and surgical patients and to differentiate it from the wider con- cepts of demoralisation and grief was the impetus which led to our devising the HAD Scale. The scale has the further advantages of providing score ranges indicating different levels of morbidity, of having been translated into most European and many Asian languages, and finally of being freely available, with scoring device, from the Medical Sciences Liaison Services of Upjohn Ltd, Fleming Way, Crawley, West Sussex RH10 2NJ.

Finally, Dr Wade states that he is not aware of "any simple measure of depression which could be used in a large number of elderly people". I should therefore like to draw attention to another validation study (Kenn et al, 1987) in which the HAD Scale was presented for use in the elderly; bearing in mind the difficulty of completion of a self-assessment scale in people who have suffered strokes, become blind, or have some other handicap, the authors of that study have presented the scale as a clinician-administered scale.

Department of Psychiatry

R. P. SNATth St James's University Hospital

Leeds LS9 7 TF

\section{References}

Zigmond, A. S. \& SNArth, R. P. (1983) The Hospital Anxiety and Depression Scale. Acta Psychiatrica Scandinavica, 67, 361-370.

Bramley, P. N., Easton, A. M. E., Morley, S. \& SNaith, R. P. (1988) The differentiation of anxiety and depression by rating scales. Acta Psychiatrica Scandinavica (in press).

SNarTh, R. P. (1987) The concepts of mild depression. British Journal of Psychiatry, 150, 387-393.

KENN, C., WOOD, H., KuCY,, M., WaTtis, J. \& CUNNANE, J. (1987) Validation of the Hospital Anxiety and Depression rating scale in an elderly psychiatric population. International Journal of Geriatric Psychiatry, 2, 189-193.

\section{Pseudo-AIDS, AIDS Panic, or AIDS Phobia}

SIR: Riccio \& Thompson (Journal, December 1987, 151,863 ) appropriately indicate that the term 'AIDSphobia' is a misnomer, and that the fear of AIDS may be part of the content of any psychopathology (affective, obsessional, schizophrenic, or delusional disorders). In general, one would agree that the fact that AIDS is the content or object is of little 